\title{
Un personaje del Persiles a la luz del Mecencio virgiliano: Bradamiro, el bárbaro violento
}

\author{
Miguel Alarcos*
}

Cuando se produce el desembarco del travestido Periandro en la Ínsula Bárbara y este es vendido a tan salvajes pobladores, un nuevo especimen «bárbaro» aparece en escena, arrogándose el derecho de posesión de la doncella comprada, sin consultar con el capitán o gobernador de los Bárbaros.

Se trata de Bradamiro, cuya presentación al lector se plasma en el inicio del capítulo cuarto del libro I, según se colige del siguiente pasaje ${ }^{1}$ :

Entre los que vinieron a concertar la compra de la doncella, vino con el capitán un bárbaro llamado Bradamiro, de los más valientes y más principales de toda la isla, menospreciador de toda ley, arrogante sobre la misma arrogancia y atrevido tanto como él mismo, porque no se halla con quien compararlo (pp. 149-150).

\section{RASGOS DEFINITORIOS DE BRADAMIRO: SU EXPRESIÓN LITERARIA}

Los segmentos subrayados ofrecen la caracterización del personaje, sustentada en una serie de estructuras sintagmáticas generadas en torno al sustan- 
tivo «menospreciador»y a los adjetivos «arrogante»y «atrevido». A efectos de contenido, tal caracterización plasma un conjunto de rasgos morales que definen automáticamente a Bradamiro, implantándose, pues, una semblanza del personaje, concebida en términos absolutos y que difiere de la heroica ${ }^{2}$.

Por otro lado, podría objetarse que la caracterización de nuestro personaje ya arranca con la expresión «de los más valientes y más principales de toda la isla», inmediatamente después de la onomástica elegida por Cervantes, esto es, Bradamiro, todo ello incluido en el pasaje sangrado líneas arriba.

En efecto, la selección de los lexemas adjetivales «valiente» y «principal» aportan al diseño del bárbaro otros rasgos caracterizadores que en modo alguno divergen del planteamiento idealizador de la novela, sino que están en consonancia con la caracterización heroica y, en concreto, con dos de los motivos literarios que refuerzan y acentúan el tópico del virtuosismo moral y/o espiritual, a saber: el de la virtus o «valor, coraje» y el de la «nobleza de origen, preeminencia social». Por lo tanto, nuestro Bárbaro, a pesar de su condición étnica, aparenta cumplir con los requisitos del estereotipo caballeresco, puesto que Periandro o, incluso - por poner otro ejemplo- el príncipe Arnaldo, son definidos de entrada en más de una ocasión con estructuras adjetivales en torno a las nociones de «valiente»y «principal».

Al igual que sucede con la formalización cervantina de los caracteres heroicos, en el caso de Bradamiro, Cervantes también recurre al fenómeno de la intensificación idealizadora, aprehendido con la lectura de la novelística griega y reelaborado conforme a sus criterios de enfatización hiperbólica: efectivamente, las nociones léxicas seleccionadas se combinan con el superlativo, dando lugar a la estructura coordinada «de los más valientes y más principales de toda la isla», giro intensificador que juega con la variante intersintagmática -o no morfológica- de este grado adjetival.

Ahora bien, el segmento «menospreciador de toda ley», que sigue a continuación de la secuencia «de los más valientes y más principales de toda la isla», introduce un sensible contraste con respecto a los contenidos formalizados hasta el momento. Además, tanto «menospreciador de toda ley» como los segmentos ulteriores en torno a los adjetivos «arrogante» $\mathrm{y}$ «atrevido», se unifican en torno a unos mismos valores semánticos y connotativos que cuestionan drásticamente la imagen caballeresca del personaje, invitando a considerar tales rasgos de «valentía» y «notariedad» como mera apariencia $\mathrm{y}$, por tanto, como cualidades no pertinentes o distintivas de Bradamiro, esto es, marginales y extrínsecas a la constitución del personaje. Dicho de otro

2. Huelga decir que Cervantes, del mismo modo que hiciera con la creación del personaje Corsicurvo (Bárbaro inaugural del Persiles), está reinterpretando, con arreglo a sus necesidades expresivas y a su propia modulación estilística, el contraste entre héroes y bandidos, ubicado en los comienzos de las Etiópicas (Fernando de Mena, 1587; López Estrada, 1954) y, en general, toda una convención del género grecobizantino, consistente en realzar a la pareja protagonista mediante su contraposición con ontologías anti-heroicas, correspondientes a piratas, bandoleros y ladrones. 
modo, se integran en la presentación del Bárbaro, pero no son elementos constitutivos de su diseño.

No obstante, la contraposición que Cervantes origina precisamente entre estos rasgos liminares y aquellos otros definitorios del bárbaro, merced al expresivo contraste entre la estructura «de los más valientes y más principales de toda la isla» y las subrayadas en el pasaje («menospreciador de toda ley, arrogante sobre la misma arrogancia y atrevido tanto como él mismo»), sirve para quebrar toda expectativa idealizadora, en una suerte de guiño irónico a la descodificación del lector, $y$, en consecuencia, contribuye a reforzar la dimensión no heroica de Bradamiro, tanto por ser miembro de la etnia de los Bárbaros como por constituir un tipo individualizado de «Bárbaro», frente al arquetipo universal y genérico que encarna Corsicurvo, figura desprovista de una caracterización específica, por medio de la cual Cervantes representa la etnia incivilizada de los Bárbaros, introduciéndonos, pues, en el particular escenario "peregrinamente peregrino» en que emerge el comienzo in medias res del Persiles e insinuándonos, por consiguiente, la superioridad de la estirpe heroica, y, de paso, sugiriendo el dialogismo con el arranque de la novela Téagenes y Cariclea.

\section{CARACTERIZACIÓN ARGUMENTAL Y NARRATIVA DE BRADAMIRO}

La definición caracterizadora que nos ilustra el pasaje se refuerza y a un tiempo se ejemplifica con el esquema argumental del capítulo cuarto y, por ende, con las acciones narrativas que tienen por núcleo central al personaje de Bradamiro, esto es, dos episodios estrechamente ligados entre sí, en clara relación de causa-efecto.

En primer lugar, observamos que Bradamiro ante la deslumbrante hermosura de quien cree ser mujer -Periandro- queda suspendido $\mathrm{y}$, encaprichado con tal mercancía, decide unilateralmente arrogarse para sí el derecho de posesión y disfrute de la misma. Esta escena constituye, por así decir, el comienzo del primer episodio clave para la interpretación del comportamiento de Bradamiro ${ }^{3}$.

Sucede después que traen a un aparente mancebo, destinado a cumplir con los ritos de la absurda profecía que rige entre estas rudas gentes, es decir, dispuesto a ser sacrificado, para luego serle extraído el corazón, del que elaborarán los mágicos polvos que han de beber los oriundos de la inhóspita Ínsula (p. 152). Sin embargo, el grito de Cloelia, que actúa como intérprete, detiene el golpe del hacha, desvelando la verdadera identidad sexual del mancebo, a

3. La escena en cuestión arranca en este pasaje: «Este, pues, desde el punto que vio a Periandro, creyendo ser mujer, como todos lo creyeron, hizo disinio en su pensamiento de escogerla para sí, sin esperar a que las leyes del vaticinio se probasen o cumpliesen» (I, 4, p. 150). 
punto de ser inmolado, de suerte que los espectadores ficticios de la escena, junto con el lector, descubren que, en realidad, es una mujer, tan hermosa como el travestido héroe (p. 153).

$\mathrm{Y}$ es aquí cuando nuestro disfrazado Periandro reconoce a Auristela, y esta a su vez a su perdido hermano, produciéndose una dramática anagnórisis entre los dos caracteres, reconocimiento que conforma uno de los puntos álgidos del episodio (pp. 153-154), para cuya resolución favorable es imprescindible el personaje de Bradamiro, aunque este no alcance a medir las consecuencias de sus actos. El episodio, por consiguiente, radica en la reacción del Bárbaro ante esta anagnórisis, lo cual es inicialmente descrito por el narrador omnisciente, para luego culminar con el parlamento que el novelista asigna a Bradamiro, tal y como se desprende de este pasaje:

Lloraban entrambos, cuyas lágrimas vio el bárbaro Bradamiro y, creyendo
que Periandro las vertía del dolor de la muerte de aquel que pensó ser su
conocido, pariente o amigo, determinó de libertarle, aunque se pusiese a
romper por todo inconveniente; y, así, llegándose a los dos, asió de la una
mano a Auristela y de la otra a Periandro y, con semblante amenazador y
ademán soberbio, en alta voz dijo: «Ninguno sea osado, si es que estima
en algo su vida, de tocar a estos dos, aun en un solo cabello. Esta doncella
es mía, porque yo la quiero, y este hombre ha de ser libre, porque ella lo
quiere» (pp. 154-155).

Observamos, en consecuencia, cómo Cervantes tiende a intensificar los rasgos caracterizadores de Bradamiro, ya no solo con el plano argumental, sino también con determinadas expresiones que plasman con plasticidad las actitudes esgrimidas por el arrogante Bárbaro. En efecto, Bradamiro decide también quedarse con la mujer que, siendo juzgada hasta entonces como varón, iba a ser sacrificada, acción que atenta contra las costumbres y reglas de convivencia de la comunidad bárbara. Por ello Cervantes recurre a una estructura concesiva, cuyo lexema fundamental estriba en la noción de «romper»: «aunque se pusiese a romper por todo inconveniente».

En la misma línea han de entenderse los grupos sintagmáticos «con semblante amenazador y ademán soberbio», utilizados por Cervantes para caracterizar en términos físicos y visuales la catadura moral de Bradamiro, definida en el inicio de capítulo. Los adjetivos «amenazador» $\mathrm{y}$ «soberbio» se integran, pues, en la red connotativa de «menospreciador, arrogante y atrevido».

La culminación de semejante actitud, que abre una brecha insólita en este mundo septentrional, se produce con las palabras pronunciadas por Bradamiro, su discurso no menos atrevido y arrogante que a todas luces confirma ese «semblante amenazador» del personaje. Este, al proclamarse dueño absoluto de la presunta doncella comprada y del aparente muchacho, reta a sus congéneres, amenazándoles con la muerte, si osan contrariar su voluntad, arremetiendo, por consiguiente, contra la autoridad del capitán.

En cuanto al segundo episodio, este se origina como consecuencia del soberbio desafío lanzado por el personaje, hasta el punto de no respetar 
siquiera la autoridad que ostenta el capitán o gobernador de los Bárbaros, como si Bradamiro se hubiese erigido súbitamente, no en uno «de los más principales», como lo es sin duda, sino en el principal por antonomasia, o sea, en el caudillo indiscutible que está por encima incluso del que es llamado Gobernador.

Se trata, pues, del brusco asesinato de Bradamiro como respuesta del indignado capitán ante tamaña rebelión, $\mathrm{y}$, a su vez, del asesinato de este por un hijo de Corsicurvo en venganza por la muerte de Bradamiro, enfrentamiento armado e inesperadas muertes que alborotan a todo el pueblo Bárbaro, incitándolos a un encarnizado combate que provoca la aniquilación de esta comunidad étnica, así como el incendio de la isla. El siguiente enunciado formaliza este segundo episodio, efecto natural del primero:

Apenas hubo dicho esto, cuando el bárbaro gobernador, indignado e impaciente sobremanera, puso una grande y aguda flecha en el arco (...) y disparó la flecha, con tan buen tino y con tanta furia que en un instante llegó a la boca de Bradamiro y se la cerró, quitándole el movimiento de la lengua y sacándole el alma (...). Pero no hizo tan a salvo el tiro, tan atrevido como certero, que no recibiese por el mismo estilo la paga de $\underline{\text { su atrevimiento, }}$ porque un hijo de Corsicurvo (...), pareciéndole ser más ligeros sus pies que las flechas de su arco, en dos brincos se puso junto al capitán y, alzando el brazo, le envainó en el pecho un puñal (...). Cerró el capitán en sempiterna noche los ojos y dio con su muerte venganza a la de Bradamiro, alborotó los pechos y los corazones de los parientes de entrambos, puso las armas en las manos de todos y, en un instante, incitados a la venganza y cólera, comenzaron a enviar muertes en las flechas de unas partes a otras... (pp. 155-156).

La violencia verbal de la que ha hecho gala Bradamiro pasa a convertirse en una cadena de acciones violentas que acaban contagiando a toda la generalidad de los Bárbaros. El vocabulario del pasaje se inserta básicamente en el campo semántico de la «violencia» y de «las armas», a la par que Cervantes echa mano de la valencia léxica «atrevido» para jugar con los ecos de la definición caracterizadora del personaje (recuérdese el segmento «atrevido tanto como él mismo»).

Por otra parte, el lenguaje hiperbólico cervantino serpea a lo largo del enunciado (subordinadas consecutivas, estructuras comparativas), como muestran las secuencias subrayadas en el pasaje, con el objeto de pintar un lienzo expresivo de la condición inculta y salvaje de esta etnia, susceptibles de caer en las más bajas pasiones e instintos, como la cólera, la venganza, la furia, la arrogancia o su predisposición a matarse, si cabe, entre ellos, o sea, al decir de Cervantes, «sin respetar el hijo al padre, ni el hermano al hermano» (p. 156).

Por lo tanto, el discurso del narrador, o incluso el parlamento del mismo Bárbaro, permiten insistir en los rasgos definitorios de Bradamiro mediante la configuración de una conducta y actitudes especialmente violentas, de manera que las nociones «menospreciador de toda ley», «arrogante» y «atrevido» 
adquieren su corroboración más concreta, materializada tanto en el plano ficcional como en el diegético.

Bradamiro es el individuo de esa peculiar sociedad que no respeta convención alguna y actúa siempre de acuerdo a sus antojos y a su propia satisfacción, pudiéndosele aplicar la máxima maquiavélica de «El fin justifica los medios», por cuanto no duda en usar la violencia, en caso de no conseguir por las buenas sus objetivos. Los cruentos sucesos que el comportamiento de Bradamiro desencadena, así como el ambiente de desorden, muertes y fragor bélico que los envuelve, inciden en la peligrosa potencialidad del personaje y enriquecen su particular diseño. En definitiva, estamos ante un personaje que desarrolla toda la expresividad connotativa de sus rasgos distintivos en medio de un duelo que desemboca en carnicería, contexto narrativo, que, a su vez, entronca con motivos literarios característicos del género épico.

\section{ANTECEDENTES Y MODELOS DEL PERSONAJE CERVANTINO: TASSO Y VIRGILIO}

Precisamente, tanto la caracterización del personaje como las situaciones argumentales de violencia en que el carácter de Bradamiro cristaliza en toda su plenitud, nos hace pensar en una serie de antecedentes que pudo tener en cuenta nuestro novelista, cuestión esta sobre la que Schevill (1908) nada apunta.

En cambio, C. Romero (2004: 150) parece ser el único crítico en sugerir la posibilidad de que nuestro personaje haya sido construido sobre el molde de ilustres arquetipos de la literatura occidental -incluyendo la clásica-, caracterizados igualmente por una violenta arrogancia, susceptible de generar trágicas consecuencias, a saber: por una parte, el caudillo etrusco Mecencio, personaje creado por Virgilio en su Eneida, y al que, por lo demás, alude Marasso (1937a y b), en relación con personajes del Quijote, sugiriendo ciertos paralelos; y, por otra, Argante y Alcastro, caracteres ambos de La Jerusalén libertada (1581; y Wasteren, 1832), epopeya, como es sabido, del renacentista Tasso. Por otro lado, Romero señala que tales arquetipos «violentos» no solo existen como creaciones épicas, sino que incluso se relacionan con las teorizaciones de las preceptivas del s. XVI, atingentes a la construcción de personajes, de manera que Cervantes pudo tener en cuenta la Filosofía Antigua Poética de López Pinciano ${ }^{4}$.

4. En el caso de las Poéticas producidas en España y coetáneas a Cervantes, destacó sobremanera la Philosophía Antigua Poética (1596) de Alonso López Pinciano, con ediciones modernas a cargo de Carballo Picazo (1953) y Rico Verdú (1998). En la Preceptiva del Pinciano la novela de Heliodoro ocupa un lugar prominente, al constituir la ejemplificación por antonomasia del «poema heroico en prosa», ideal de elaboración novelística vigente en la época, al que aspiraban los novelistas que pretendían forjarse como tales. Cervantes pudo leer este manual y conocer así varios aspectos 
Sin embargo, el cervantista maneja estos datos para argumentar sus hipótesis sobre la fecha o proceso de composición del Persiles, comparando finalmente a Bradamiro con un «desaforado bárbaro fanfarrón» del Quijote (I, 47), que aparece en la historia intercalada del canónigo de Toledo, de suerte que su interés primordial no consiste en explicar la tradición clásica que opera en la novela cervantina, por lo que deja a otros investigadores la labor de «identificación del modelo, si lo hubiere» y, por tanto, el cotejo entre Bradamiro y los arquetipos de Virgilio y Tasso.

\section{DE MECENCIO A SUS REMINISCENCIAS EN EL DISEÑO DE BRADAMIRO (CARACTERIZACIÓN Y DESARROLLO ARGUMENTAL)}

Y es en este punto, donde, tras examinar la caracterización de Bradamiro, así como los medios lingüísticos de que dispone Cervantes para forjarla, el análisis propiamente intertextual puede -y debe- reanudarse, exigiendo la delimitación de reminiscencias, tanto en el pasaje definidor de I, 4 como de cara al diseño mismo del personaje y las estructuras argumentales que apuntalan sus actitudes y conducta, y, en fin, sus acciones narrativas.

A tales efectos, veamos ahora qué rasgos definen a Mecencio ${ }^{5}$, a fin de aquilatar el grado de vinculación entre ambos personajes y, sobre todo, en qué medida la presentación de Bradamiro se fundamenta en hipotextos virgilianos.

Mecencio es uno de los aliados de Turno en la guerra entre Teucros y Latinos, alentada por la diosa Juno, para impedir las bodas entre Lavinia, hija del rey del Lacio, y el héroe troyano, Eneas. El personaje, notorio caudillo etrusco y rey de los Trirrenos, aparece por vez primera en el Libro VII, encabezando la enumeración de tropas auxiliares del monarca rútulo (vv.

de la praxis ficcional y estética de Heliodoro, que, a su vez, entroncaba con varios de los rasgos de la épica virgiliana. Entre los teóricos italianos anteriores al Pinciano, destaca Torquato Tasso que en sus Discorsi sull' arte heroica (1567-1570) esgrime presupuestos afines a la Filosofia Antigua Poética, «calificando de poemas épicos en prosa no sólo los libros de caballerías sino las ficciones sentimentales del tipo de Las Etiópicas, citadas por él explícitamente» (Pelorson, 2003: 28), si bien «el aprecio fugaz que mostró el Tasso hacia Heliodoro dista mucho, en nuestra opinión, de poder equipararse con el entusiasmo y la precisión del Pinciano». Para una edición moderna de semejante Preceptiva, véase Poma (1964). En cualquier caso, al margen de su distinta predilección por Heliodoro, ambas Poéticas comparten otras ideas estéticas, cuya huella en el Persiles es evidente, y que van más allá del «poema épico en prosa», es decir, todo lo relativo a las características del género épico, tal y como quedó estipulado por sus cánones occidentales, esto es, Homero y Virgilio, y, entre ellas, la tipología de caracteres y sus estereotipos.

5. Para conocer en profundidad la figura virgiliana de Mecencio, al margen de toda relación intertextual con Cervantes o, en general, con la literatura española, remitimos a los artículos de González Vázquez (1979-1980) y Oroz (1981), magistrales enfoques del asunto desde perspectivas metodológicas muy próximas a la nuestra, como lo constituye la aplicación de la Estilística al campo de la filología clásica. 
641-817), y su presencia jalona los libros posteriores, cuya temática general comprende la descripción de la contienda, hasta el XI, en que Mecencio ya es un cadáver, consagradas al dios Marte sus fulgentes armas (vv. 7-16), y donde, por lo demás, las huestes latinas se dispersan con la muerte de la guerrera Camila, reservado, pues, el Canto XII para el enfrentamiento final entre Eneas y Turno.

Para completar el esquema argumental en que se inserta la figura de Mecencio, es menester señalar que tal personaje adquiere cierto protagonismo en los vv. 689-908 del Libro X, por tres situaciones fundamentales: la ausencia temporal de Turno, para lo cual Mecencio asume el mando del ejército rútulo, destacando por sus proezas; la muerte por Eneas de Lauso, el hijo de Mecencio; y el regreso de este al campo de batalla para vengar la muerte de su vástago, encontrando en esa misma venganza su propia muerte a manos de Eneas.

En consecuencia, Mecencio es un personaje estrechamente vinculado con un ambiente de violencia, envuelto en multitud de refriegas, carnicerías y combates, del mismo modo que el personaje cervantino se asocia a un ambiente de belicosidad manifiesta y al estallido de una específica guerra, por lo que la articulación diegética e imaginativa de Bradamiro presentaría, por muy generales que sean, reminiscencias semánticas de los libros VII-XII, especialmente, la franja argumental comprendida entre el VII y el X, donde se concentran las acciones guerreras de Mecencio.

Por lo tanto, para la elaboración del «segundo episodio» en torno a la figura del Bárbaro, Cervantes habría asimilado estos materiales épicos, de suerte que dicho episodio vendría a ser una síntesis muy comprimida de las características ambientales que se asocian inevitablemente a la figura de Mecencio. En este sentido, el tratamiento cervantino no resulta innovador, sino todo lo contrario, si bien el conjunto de elementos conservados experimentan inevitables cambios, al adaptarse a las necesidades expresivas de Cervantes, a la estructura narrativa del capítulo y -cómo no- a la lengua literaria del novelista.

Ahora bien, pese a esta convergencia general, las funciones de ambos caracteres en la génesis de sus respectivos contextos es bien distinta: mientras Mecencio acude en auxilio de Turno, quien realmente declara la guerra a Eneas, Bradamiro influye decisivamente con sus arrogantes actitudes en el enfrentamiento armado de los Bárbaros. Añádase el hecho objetivo de que la guerra de los Bárbaros es una guerra civil o intestina, en la que pelean entre sí, sin que existan enemigos en calidad de invasores, ni aún cuando Periandro, Auristela y el resto de prisioneros son verdaderos intrusos en la Ínsula. Estas diferencias, a nuestro modo de ver, muestran en qué consiste la reelaboración cervantina, esto es, en el proceso de irritación hiperbólica con respecto a lo que se considera todo un modelo arquetípico.

Se trata, por consiguiente, de un tratamiento que, al tiempo que innova, amalgama conservadurismos. El episodio persiliano, en cuanto síntesis del contexto en que se articula la figura virgiliana, es a su vez una síntesis que 
invierte características del mismo, con el fin de estirar al máximo sus potencialidades imaginativas o ficcionales, con arreglo a los principios de enfatización hiperbolizadora que presiden la composición de la novela.

Si comparamos con mayor detenimiento las historias de Mecencio y Bradamiro, resulta evidente la existencia de un esquema argumental común a ambos personajes, segmentable en dos elementos diferenciados.

Por una parte, tanto uno como otro se ven involucrados en un enfrentamiento -ya puramente verbal, ya en forma de duelo- con otro personaje, enfrentamiento que les cuesta la vida: tras una primera tentativa frustrada, de la que sale herido y es forzado a retirarse, Mecencio arremete de nuevo contra Eneas, quien lo mata finalmente, como se desprende de la lectura de los vv. 689-908 del Libro X; por lo que toca a Bradamiro, este, sin llegar a empuñar lar armas, desafía con amenazadoras palabras al capitán de los Bárbaros, quien igualmente le da muerte, replicando tal atrevimiento con una mortal flecha, asesinato que, por lo demás, será motivo o detonante de la guerra civil entre los pobladores de la Ínsula.

Por otra, el enfrentamiento -entendido como categoría general-, así como la muerte de uno de los combatientes, incorpora a su esquema la noción de «venganza», la cual se encarna en un determinado personaje: así, en el caso de Virgilio, comprendemos por qué Mecencio ataca por segunda vez a Eneas, esto es, tratando de vengar la muerte de su hijo Lauso, que había sido derribado previamente por el mismo caudillo troyano; con respecto al caso de Cervantes, sabemos de la irrupción en escena de un tercer personaje, un hijo de Corsicurvo, que apuñala mortalmente al capitán con el objeto de vengar el asesinato de Bradamiro, estallando a continuación la guerra civil.

Por lo tanto, aunque la trayectoria de Mecencio es mucho más extensa que la de Bradamiro -reducible a dos episodios del Persiles, I,4-, la elaboración argumental de ambos caracteres confluye en un mismo esquema abstracto: el funcionamiento de una situación dialógica o, si se prefiere, dialéctica, apoyada en un intercambio de réplicas mediante las armas, en el que tres sujetos -a lo sumo- participan o se ven afectados por ello, esto es, la tríada virgiliana constituida por Lauso, Mecencio y Eneas y la de Cervantes, conformada por Bradamiro, el capitán de los Bárbaros y un hijo de Corsicurvo.

En el caso de Virgilio, esta definición gana en complejidad merced al tratamiento específico aplicado en los vv. 689-908 del libro X, lo que podemos representar del siguiente modo:

$\underline{\text { Mecencio }}$ se enfrenta a Eneas $>$ Eneas lo hiere $>$ Lauso $s e$ enfrenta a Eneas

$>$ Eneas lo mata

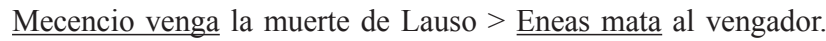

Cervantes, en cambio, simplificará la compleja trama dialéctica que impera en los episodios finales de Mecencio, acercándose mucho más al esquema situacional común a la Eneida y al Persiles, si bien, en clara divergencia con Virgilio, el vengador de la muerte de Bradamiro no fracasará en su vengan- 
za, lo que constituye una inversión del elemento virgiliano. La reelaboración cervantina podría representarse de esta manera:

Bradamiro se enfrenta al capitán $>$ el capitán lo mata $>$ un hijo de Corsicurvo venga la muerte de Bradamiro $>$ El capitán muere a manos del hijo de Corsicurvo (= El capitán no mata al vengador).

En consecuencia, Cervantes se muestra conservador en la apropiación de materiales, al tiempo que realiza los cambios que considera pertinentes.

Como vemos, no solo se fijó en el contexto general de la figura de Mecencio y en el ambiente de violencia guerrera que tamiza los episodios relativos al caudillo etrusco a lo largo de los libros VII, VIII, IX y X de la Eneida, sino que también asimiló la construcción argumental que define a los vv. 689-908 del libro X, por lo que el «segundo episodio» que hemos dado en llamar, en relación con Bradamiro, contaría con un influjo virgiliano más específico, es decir, con reminiscencias semánticas, bien concretas, de orden ficcional.

Por consiguiente, el personaje virgiliano de Mecencio aporta elementos argumentales - de carácter general o ya más de detalle- que, pasados por la criba reelaboradora de Cervantes, se incorporan como sedimentos a la estructuración narrativa y ficcional de la figura de Bradamiro, contribuyendo naturalmente a realzar la caracterización de este Bárbaro individualizado.

Ahora bien, la verdadera prueba de que el personaje cervantino se fundamenta en el arquetipo de Mecencio no consiste tanto en la existencia de convergencias y afinidades relativas a la atmosfera o al argumento, como en la confrontación de sus respectivas caracterizaciones o diseños.

La primera aparición de Mecencio en la Eneida se corresponde exactamente con su presentación al lector, presentación que ofrece los rasgos distintivos del personaje, según podemos ver en los vv. 647-648 (En., VII) ${ }^{6}$, mientras se nos describe un catálogo de ejércitos auxiliares, que acuden en ayuda de Turno:

Primus init bellum Tyrrhenis asper ab oris

contemptor divum Mezentius agminaque armat

Hemos subrayado los elementos que, a nuestro juicio, arrojan luz sobre la caracterización del personaje virgiliano, y que, como veremos, se revelaran como las estructuras hipotextuales, sobre las que se fundaría el pasaje caracterizador de la figura cervantina.

Para empezar, el nombre propio Mezentius viene calificado por el epíteto asper, adjetivo, como se sabe, contrapuesto a levis,-e («liso, leve, ligero»),

6. Manejamos la constitución textual de Mynors (1969); en cuanto a la traducción, remitimos a las excelentes versiones de Gregorio Hernández de Velasco (1555: Bejarano, 2000) y a la moderna de P. Hernúñez (2003). 
lo cual viene a configurar una escueta definición del arquetipo que ha diseñado Virgilio. En efecto, el adjetivo seleccionado por Virgilio comporta los significados de «áspero, duro, severo, huraño», cuando es aplicado a personas, de manera que la figura de Mecencio ya se ve empañada por connotaciones negativas, de corte psicológico y moral. Un estudio léxico del adjetivo asper, así como de sus potencialidades connotativas, demostraría que, con independencia de su esfera de aplicación, apunta a la noción general de «violencia» ${ }^{7}$.

Por lo tanto, el caudillo etrusco de entrada ya constituye un individuo antagónico a las connotaciones morales, de orden positivo, que impregnan la figura del héroe troyano, protagonista de la epopeya,

Es, sin embargo, la expresión contemptor divum la que formaliza la esencialidad caracterizadora del personaje, de manera que Mecencio no solo es una persona dura y huraña, capaz de generar antipatía en el prójimo, sino que incluso desprecia o desdeña a los dioses, lo que en última instancia sugiere que no respeta en absoluto el ordenamiento ético establecido por estos para el funcionamiento armonioso de cuanto han creado, esto es, la naturaleza $\mathrm{y}$, en especial, la convivencia humana. La selección léxica del sustantivo contemptor, que significa «despreciador» y que deriva del verbo contemno («despreciar») ${ }^{8}$, refuerza, pues, la sucinta definición del personaje que conlleva el epíteto asper y, a un tiempo, contribuye a especificar su alcance connotativo.

El diseño de Mecencio, pues, gira en torno a dos rasgos caracterizadores: la aspereza de carácter y su desdén hacia las leyes divinas, insinuándose, en consecuencia, la configuración de un arquetipo que choca brutalmente con el eje del bien y que carece de todo escrúpulo, no solo con respecto al plano religioso o sacro, sino también, por lo que concierne a su relación con el resto de los hombres. Su caracterización se supedita implícitamente a la noción genérica de «violencia», a lo que ha de sumarse su particular articulación argumental en el Libro X y -claro está- el contexto de arrogante belicosidad, en que se insertan sus acciones a lo largo de los libros VII, VIII, X y XI.

7. En efecto, el adjetivo en cuestión, aplicado a terrenos, por ejemplo, significa «áspero», «con rugosidades», «con relieves», como podemos ver precisamente en Virgilio, en En., $V$, v. 267: cymbia aspera signis. El propio Virgilio vuelve a utilizar el adjetivo para expresar la idea de un «mar tempestuoso, erizado, encrespado», en suma, violento: maria aspera (En., VI, v. 351). Aplicado a animales, el adjetivo implica igualmente la noción de «violencia, amenaza», como resulta patente en otra expresión virgiliana, referido a un buey en concreto: interdum aspera cornu (Georg., III, v. 57), es decir, «que amenaza con sus cuernos».

8. La lengua latina dispone de una gran riqueza de derivados del verbo temno («despreciar») que, según Bréal y Bailly (1922: 386), «est probable que le sense primitif est "couper"». El fonema labial sordo /p/, que aparece en estas formas derivadas, como por ejemplo contemptor, se debería, de acuerdo con estos autores, a un reajuste puramente eufónico, «comme dans emptus, emptor». Entre estos derivados, se encuentran el sustantivo virgiliano y el verbo compuesto contemno, y todos ellos se insertan exclusivamente en el campo semántico del «desprecio» o «desdén», sin que haya ningún otro matiz o connotación reseñables. 
La caracterización conformada en los vv. 647-648 se acentúa y toma cuerpo con el ejemplo de sus acciones, según se colige de los vv. 481-488 de la En., VIII, realizadas, no en un campo de batalla, sino durante el ejercicio de su gobierno como rey de una floreciente colonia lidia -los Trirrenos-, situada entre los montes de Etruria. Este episodio de la historia de Mecencio se integra en el parlamento de Evandro, rey de Arcadia que acoge como huésped a Eneas:

Hanc multos florentem annos rex deinde superbo

Imperio et saevis tenuit Mezentius armis.

Quid memorem infandas caedes, quid facta tyranni

effera? Di capiti ipsius generique reservent!

Mortua quin etiam iungebat corpora vivis

componens manibusque manus atque oribus ora,

Tormenti genus, et sanie taboque fluentes

Complexu in misero longa sic morte necabat.

Hemos subrayado determinadas expresiones en el texto poético, con el único fin de hacer ver la persistencia de las «violentas» connotaciones que se acumulaban en los vv. 647-648 de la En., VII.

Efectivamente, Virgilio comienza por definir la conducta del rey de los Trirrenos, indicando que gobernaba la colonia con «soberbio mando» y con «crueles armas», para lo cual construye dos grupos sintagmáticos en ablativo, superbo imperio y saevis armis, estructuras simétricas, a juzgar por su esquema morfosintáctico de adjetivo (superbo y saevis) + sustantivo (imperio y armis), así como por la afinidades léxicas entre los epítetos superbo y saevis, y no menos entre los sustantivos imperio y armis, adscritos al paradigma de la «guerra».

Con lo cual, la áspera caracterización de Mecencio se enriquece con los matices de «soberbia» y «crueldad», que en los versos ulteriores se confirmarán, ya no solo por la selección léxica efectuada y por la plástica red connotativa del fragmento, sino también por los hechos y acciones conformadas en el mismo, que configuran un episodio emblemático y altamente ejemplificador de la trayectoria del personaje.

El poeta latino prosigue con la semblanza pragmática de Mecencio, introduciéndonos en las acciones que lo caracterizan, cuyo recuerdo resulta cuanto menos agradable: la soberbia y crueldad de su gobierno (superbo imperio y saevis armis) se especifica ahora con las expresiones infanda caedes y facta tyranni effera, de manera que Mecencio es retratado como el autor de monstruosas matanzas - casi imposibles de describir con palabras- y, por ende, como un monarca que ha ejercido su poder tiránicamente, emprendiendo salvajes acciones.

Hay, pues, tres núcleos de expresividad en este segmento interrogativo: caedes, cuya significación resulta hiperbólica, al combinarse con el adjetivo infandas; el genitivo tyranni que intensifica particularmente el superbo imperio; y el adjetivo effera que recoge los ecos de saevis armis, adjetivo con 
el que se califican los facta del caudillo, siendo la estructura facta tyranni effera una aposición intensificativa del grupo sintagmático infandas caedes.

Por lo tanto, el diseño de Mecencio se concretiza con nuevos rasgos adicionales, rasgos que permiten calibrar el jaez de sus actitudes y comportamiento, fuera del combate o del escenario bélico: su exacerbado carácter sanguinario o criminal, según se deduce de infandas caedes; y su salvaje poder tiránico, como trasluce la secuencia facta tyranni effera. Hasta aquí puede decirse que la expresión contemptor divum, núcleo de la caracterización abstracta del personaje, no solo se esclarece, sino que adquiere toda su plenitud semántica, puesto que la conducta del personaje atenta precisamente contra las pautas marcadas por los dioses, haciéndose cada vez más acusada la relación entre Mecencio y la idea de «violencia».

Finalmente, la culminación expresiva y connotativa de contemptor divum, así como de todo el entramado semántico descrito hasta ahora, que incide en el diseño del personaje (la soberbia y crueldad tiránicas de su poder y sus acciones inefablemente sanguinarias y salvajes), se origina con los últimos versos del fragmento acotado, es decir, desde mortua quin etiam iungebat corpora vivis hasta sanie taboque fluentes / complexu in misero longa sic morte necabat.

Esta sección del fragmento ilustra la ejemplificación más plástica del comportamiento de Mecencio y, por tanto, eleva al personaje a la categoría de rotundo criminal, ofreciendo una descripción tan dramática como truculenta de los asesinatos ejecutados por el despiadado y desdeñoso monarca. La función intensificadora que ejercen estos últimos versos en relación a los anteriores queda puesta de relieve con la presencia del elemento enfático quin («hasta qué punto»), en combinación con el adverbio etiam, que en este contexto significa «incluso».

No vamos a insistir sobre el léxico utilizado para conformar el pasaje, como por ejemplo la asociación de mortua corpora con vivis y la posterior enumeración que la concretiza (manus manibus y ora oribus), o bien el verbo necabat, intensificado con la metáfora complexu in misero y la expresión longa morte («larga agonía»), verbo que por lo demás expande los ecos expresivos de infandas caedes. En conjunto, la carga semántica de los vocablos, tal y como muestran los términos destacados por nosotros, realza el carácter sanguinario y salvaje del caudillo etrusco y consolida, por tanto, la tónica siniestra que unifica su caracterización.

Destaca sobremanera el empleo del ablativo tabo, del neutro tabum, - $i$, que constituye el núcleo de significación más contundente de todo el conjunto, ya que su noción es la de «sangre corrompida, pus, podre», con lo que se plasma el detalle más tremendista o escabroso de la descripción, cerrando así Virgilio con contundente y definitivo remate el alcance expresivo de contemptor divum $\mathrm{y}$, por consiguiente, el diseño de Mecencio, que rezuma a todas luces violencia a borbotones, incluso fuera del campo de batalla.

Por lo que atañe al personaje cervantino, no hay duda de que su diseño se inspira sensiblemente en el de Mecencio. Sus específicos comportamientos 
remiten connotativamente a la violencia. En cuanto a sus rasgos distintivos, en líneas generales apuntan a la arrogancia, al no respeto y al elemento del «desprecio». A la luz de estos datos también cobran fuerza -creemos- la influencia argumental y contextual que señalamos anteriormente, a propósito de los vv. 689-908 del Libro X, en cuanto sedimento del episodio de Bradamiro, concerniente a las consecuencias de su amenaza verbal, esto es, su inesperada muerte y el estallido de la guerra civil entre los Bárbaros.

Por otra parte, al igual que Virgilio, la caracterización de Bradamiro consta de dos secciones: por un lado, su definición abstracta, conformada en el pasaje de presentación; y por otro, la narración de sus acciones, palabras y actitudes, en la idea de aportar a semejante retrato una mayor ejemplificación o concreción que lo refuerce e intensifique. Naturalmente, al aplicar esta plantilla general, uno y otro autor manifiestan sus divergencias: los episodios persilianos no participan de la truculenta crudeza, de la que hace gala el episodio sobre las matanzas y género de torturas, atingente a Mecencio, sino de la atmósfera y determinados detalles que presentan los vv. 689-908 del Libro X, referentes al juego de violentas réplicas, a raíz de la muerte de Lauso.

\section{EL INFLUJO DE LA EXPRESIÓN VIRGILIANA \\ EN LA CARACTERIZACIÓN DE BRADAMIRO: REMINISCENCIAS FORMALES DEL DISEÑO DE MECENCIO}

No obstante, los resortes de la reelaboración cervantina respecto del arquetipo encarnado por Mecencio estriban no tanto en el funcionamiento de reminiscencias semánticas, concernientes al plano de la caracterización del personaje, como en la expresión literaria de dicha caracterización.

Volvamos la vista, pues, al pasaje de presentación de Bradamiro en I, 4 y, muy en especial, a las secuencias subrayadas, siguiendo así una técnica habitual en nuestros cotejos entre texto origen y texto adoptivo, cuando los materiales reelaborados preponderantes se definen como reminiscencias formales, aunque lleven aparejadas modificaciones del contenido hipotextual, dejando la negrita para marcar tramos, sensiblemente influenciados, por ideas o nociones,

Entre los que vinieron a concertar la compra de la doncella, vino con el capitán un bárbaro llamado Bradamiro, de los más valientes y más principales de toda la isla, menospreciador de toda ley, arrogante sobre la misma arrogancia y atrevido tanto como él mismo, porque no se halla con quien compararlo (pp. 149-150)

y a un tiempo comparémoslo con el hipotexto virgiliano que nos materializan los vv. 647-648 de la En., VII, donde igualmente es ilustrativo el subrayado:

Primus init bellum Tyrrhenis asper ab oris contemptor divum Mezentius agminaque armat. 
En primer lugar, tanto Virgilio como Cervantes coinciden en el empleo del lexema «despreciador», que en el ámbito originario se expresa con el sustantivo contemptor, mientras que en el Persiles se recurre a su equivalente castellano, esto es, «menospreciador». En términos de caracterización de personajes, es evidente que Bradamiro cuenta, entre sus rasgos distintivos, con uno idéntico al que define por excelencia a Mecencio, constituyendo, en consecuencia, un indicio de conservadurismo en el tratamiento reelaborador de Cervantes. El diseño del personaje cervantino presenta, pues, una reminiscencia virgiliana, no solo de contenido lexemático, sino de expresión léxica, con la salvedad de que Cervantes no escribe en latín y, para mantener la fidelidad al texto origen, ha de acudir al vocablo equivalente en español áureo. Sería este, en consecuencia, el elemento conservador de la caracterización del Bárbaro.

Sin embargo, mientras Virgilio combina su sustantivo con el genitivo plural divum, Cervantes altera semejante combinatoria, implantando la suya propia, es decir, asociando «menospreciador» con el grupo sintagmático «de toda ley». Si bien se mantiene fiel a la factura sintáctica de la secuencia contemptor divum (núcleo + adyacente nominal), la divergencia se manifiesta en el plano semántico, esto es, en la elección léxica del complemento nominal del sustantivo: en vez de la valencia «dioses», tenemos la opción «ley», formalizada con la estructura «de toda ley». Por lo tanto, en la expresión cervantina menospreciador de toda ley opera un hipotexto de la En., VII, esto es, contemptor divum.

Cervantes, por consiguiente, reelabora la expresión poética de Virgilio, desarrollando con su lengua literaria las potencialidades expresivas y posibles connotaciones de divum, si tenemos en cuenta la contextualización que rodea a los vv. 647-648, así como los diversos episodios protagonizados por Mecencio, que enfatizan su diseño y esclarecen el significado de contemptor divum, en particular, los vv. 481-488 del libro VIII, consagrado a los crímenes del soberano etrusco. De aquí que, si Mecencio atenta contra los dioses e implícitamente, dada la naturaleza de su carácter y acciones, contra las leyes establecidas por la divinidad, Cervantes prefiera especificar el genitivo plural con la expresión «de toda ley», de manera que Bradamiro, en cuanto «menospreciador de toda ley»-y no simplemente * «menospreciador de los dioses»-, se erija en trasunto Bárbaro de Mecencio, proclive a arremeter contra todo tipo de ley, sea de los dioses, sea de los hombres, esto es, la ley de Dios, que es simultáneamente el justo ordenamiento que debe regir entre los seres humanos, de acuerdo con la ideología cristianizadora que destila el Persiles.

Esta reelaboración globalizadora le permite a nuestro novelista, ya de cara al conjunto de la Historia Septentrional, insistir en la condición de «Bárbaro» de Bradamiro y, por tanto, en su ontología no heroica, de paso que exalta los valores evangelizadores del etnocentrismo católico de la época. Paralelamente, el hipotexto virgiliano del segmento «menospreciador de toda ley», aplicado a la caracterización de Bradamiro, le sirve para reelaborar 
nuevamente la figura de bandidos y piratas, convención característica de la tradición heliodórica.

No hay duda, pues, de las funciones estructurantes y descodificadoras que adquieren estos materiales reelaborados del pasaje cervantino, y ello ya define, a todas luces, la mayor relevancia estética del mismo, frente a los otros casos del repertorio, meramente bosquejados en sus generalidades y características.

En segundo lugar, el diseño de Bradamiro no contempla, a bote pronto, el rasgo distintivo de Mecencio, consistente en su aspereza de carácter, plasmado por el epíteto asper. La comparación de ambos textos evidencia que el epíteto virgiliano es omitido por Cervantes, de modo que ni siquiera podemos encontrar un término equivalente en español o sinónimo del vocablo latino. En su lugar aparecen, sin embargo, los adjetivos arrogante y atrevido ${ }^{9}$, que se complementan con la secuencia «menospreciador de toda ley» y que, por tanto, constituyen los rasgos diferenciales de Bradamiro, comparado con Mecencio.

Empero, no podemos olvidar que el asper Mezentius contemptor divum, una vez que se leen los vv. 481-488 del Libro VIII, se explicita en un sujeto con hiperbólicas dosis de soberbia, crueldad y salvajismo, lo que, a efectos connotativos, tiende un puente con la arrogancia y atrevimiento definitorios de Bradamiro. Por consiguiente, Cervantes estaría reelaborando con parámetros más innovadores la herencia expresiva del adjetivo asper, así como sus ulteriores ecos léxicos en el episodio de las matanzas y torturas ejercitadas por Mecencio. Frente a la concisión formal virgiliana, que se limita a incrustar en la presentación un solo adjetivo, la doble adjetivación cervantina de «arrogante» y «atrevido» vendría a explicitar, como si se tratara de una especie de deconstrucción semántica o descomposición en unidades menores, todo el engranaje de nociones aglutinadas en torno a Mecencio, engranaje que Virgilio sintetiza con la selección léxica de asper.

Por último, hemos de fijarnos precisamente en los otros elementos destacados en negrita, que no son otra cosa que desarrollos enfáticos de los adjetivos «arrogante» y «atrevido». La reelaboración del adjetivo virgiliano asper $\mathrm{y}$, por tanto, de la aspereza definitoria de Mecencio se completa con la concepción hiperbolizadora cervantina que fluye a lo largo de todo el Persiles, muy diversificada en sus formas y recursos estilísticos, concepción que, por lo demás, como ya sabemos, se fundamenta en la tendencia intensificadora de los novelistas griegos, vinculada estrechamente con el fenómeno idealizador, y tiene por objeto renovar, a modo de crítica revisión, convenciones formales y clichés inherentes al género, en que se inscribe Heliodoro.

9. De ahí que en los textos anteriores confrontados, y, después, en las explicaciones, junto a la intercalación de los términos pertinentes, hayamos optado por la negrita como realce tipográfico distinto del subrayado, cuya función, como se habrá inferido, es poner de relieve los aspectos convergentes entre Cervantes y Virgilio. La negrita, pues, la utilizamos para resaltar los elementos diferenciales de ambos textos, el virgiliano y el cervantino. 
En el contexto presente la hiperbolización cervantina se torna degradadora, a juzgar por los rasgos caracterizadores de Bradamiro y, por tanto, por sus connotaciones antiheroicas. En efecto, el adjetivo «arrogante» se enfatiza con el segmento pleonástico o anafórico sobre la misma arrogancia, en un nítido juego estilístico de figura etimológica, por cuanto Cervantes echa mano de vocablos con la misma raíz /arrog-/, pertenecientes a una misma familia léxica, pero distintos en su categorización morfológica, ya que el primero es adjetivo y el otro sustantivo.

Por otra parte, debe señalarse que «arrogancia» es sustantivo de índole abstracta, que, unido al cuantificador «misma», nos plasma la personificación de esta propiedad definitoria de Bradamiro o, en otras palabras, la Arrogancia con mayúsculas. Si añadimos que la estructura enfática viene precedida de la preposición «sobre», es evidente que Cervantes construye una suerte de comparación hiperbolizadora, mediante la cual el arrogante carácter del Bárbaro no solo es parangonable con su propia abstracción -el concepto de «arrogancia»-, sino que incluso aventaja o supera con creces dicho concepto, es decir, Bradamiro es la personificación hiperbólica de la Arrogancia, uno de los defectos capitales condenados por el código ideológico de Cervantes ${ }^{10}$.

Por lo que atañe al adjetivo «atrevido», la estructura que lo enfatiza se halla en la misma línea que la anterior, fruto, pues, de una hiperbolización, de corte degradador. En esta ocasión, la secuencia en negrita tanto como él mismo consiste en una comparación directa, en base a la correlación «tanto como», que viene a traducir combinaciones similares cultivadas por la novelística griega. No obstante, el símil desarrollado por Cervantes atrevido tanto como él mismo carece del relieve intensificador que manifiesta la expresión arrogante sobre la misma arrogancia: si en aquel caso Bradamiro se constituía en la quintaesencia de la arrogancia, del mismo modo que Auristela con respecto a la hermosura, ahora su carácter audaz o atrevido es comparable al propio sujeto que encarna esa cualidad defectuosa o imperfecta, en una relación puramente tautológica.

Sin embargo, la secuencia intensificadora en torno a «atrevido» se redondea al fin y al cabo en consonancia con la rotunda expresividad de «arrogante sobre la misma arrogancia»: en efecto, justo a continuación del giro «tanto como él mismo», se atestigua, a modo de glosa o aclaración justificativas, una subordinada causal porque no se halla con quien compararlo. Esta subordinada tiene por función encarecer hiperbólicamente el símil precedente, merced no solo a la modalidad negativa de la expresión y al giro habilitado a este fin («no se halla...»), sino también al juego cervantino con el concepto

10. Análogo procedimiento se encuentra, por cierto, en uno de los giros más frecuentes aplicados a la hermosura de la heroína Auristela: hermosa sobre la misma Hermosura. El contenido conformado en ambas secuencias es más o menos el mismo, con la diferencia de que en el caso de Bradamiro se juega con lexemas de connotaciones negativas, con arreglo a criterios de intensificación degradadora, mientras que en el caso de Auristela las connotaciones son positivas, en consonancia con el ideal heroico $\mathrm{y}$, por tanto, con la intensificación idealizadora tan característica de la novela cervantina. 
de «comparación»y, por ende, con sus estrategias retóricas («...con quien compararlo», cláusula comparativa), juego que adquiere ciertos visos metaliterarios y metalingüísticos, ya que los ecos de la correlación «tanto como» parecen reproducirse en el uso de la forma verbal «compararlo», así como en la propia utilización de la cláusula «con quien compararlo».

Pues bien, a tenor de este análisis, comprobamos que la caracterización del personaje cervantino se formaliza bajo las exigencias de la retórica intensificadora que impera en el Persiles, de modo que los rasgos distintivos atingentes a lo «arrogante» y «atrevido» presentan una fisonomía sumamente hiperbolizada, lo que sin duda refuerza el alcance expresivo del segmento «menospreciador de toda ley».

Además, a raíz del fenómeno hiperbolizador, estos rasgos trascienden sus propios límites semánticos, redefiniéndose como exagerados arquetipos de la imperfección moral, esto es, susceptibles de expresar valores absolutos que invierten, por así decir, el virtuosismo definitorio de los héroes. En otro orden de cosas, Cervantes no solo acomete modificaciones semánticas y formales en el texto origen, sino que proyecta su personal reelaboración estilística, basada en los procedimientos de enfatización hiperbólica.

\section{EN TORNO A LA ONOMÁSTICA DEL PERSONAJE Y SU DENSIDAD EXPRESIVA}

Para terminar con el estudio del influjo virgiliano en la configuración de Bradamiro, no podemos soslayar la onomástica del personaje, otra de las innovaciones que comporta el tratamiento reelaborador de Cervantes.

Aunque el novelista no echa mano de raíces y/o sufijos grecolatinos, la denominación Bradamiro es suficientemente ilustrativa del arquetipo creado por Cervantes, por cuanto resalta la ontología violenta, áspera y desdeñosa del personaje, en contraste con los protagonistas de la Historia Septentrional y su séquito, sujetos a una fuerte idealización física y moral.

En efecto, siguiendo lo que nos parece una acertada interpretación, esto es, la de Romero (2004: 150), Bradamiro vendría a ser una deformación fónica del compuesto eslavo Vladimir, donde vlad o vladéti es «poder, señorío» y mari «grande, famoso», de suerte que el vocablo en conjunto equivaldría a la significación «ilustre por su poder». Ahora, si se tiene en cuenta que en ruso mir connota el valor de «paz», entonces Vladimir habrá de interpretarse con la acepción de «señor, príncipe de la paz», lo que constituiría el núcleo significativo plasmado en la onomástica cervantina Bradamiro ${ }^{11}$.

11. Por convincente que parezca la exégesis de Romero, se nos puede objetar que Cervantes carecía de conocimientos sobre las lenguas eslavas, particularmente, sobre el ruso. No obstante, no resultaría inverosímil que tuviera constancia de las aclaraciones, de orden léxico (con indicación de los vocablos originarios, su significado y su equivalente latino), que incluían las descripciones geográficas 
Bajo esta última acepción, el nombre del personaje cervantino, caracterizado por su violenta arrogancia y beligerante osadía, habría de explicarse -en términos de contenido- como una deformación o degradación irónicas del Vladimir eslavo-ruso ${ }^{12}$, puesto que la definición onomástica «príncipe de la

y etnográficas divulgadas en la época en torno al Septentrión europeo, cuyos autores más representativos, especialmente, por su posible recepción cervantina, fueron Olao Magno (1539 y 1555), Abraham Ortelio (1570 y 1578) y Francisco de Támara (1556). Además, como ha puesto de manifiesto Lozano Renieblas (1998: 102-103), documentándose, a tales efectos, en los mismos Olao Magno y Ortelio, el imaginario norteño del Persiles integra asociaciones con lugares reales del dominio eslavo, como Lituania, $\mathrm{y}$, en el ámbito estrictamente lingüístico, incorpora «la lengua polaca» como un lenguaje hablado y entendido por personajes, de diversas latitudes norte-europeas, en distintos escenarios de esa geografía extrema (Transila negociando con el príncipe danés Arnaldo la compra de Periandro en la Isla Bárbara; y el propio Periandro, en su encuentro con Sulpicia y el rey Cratilo, en Bituania), de manera que con tal noción Cervantes no parecería designar la «lengua específica de Polonia», sino, como asegura Lozano Renieblas (1998: 103), "una lengua común a todos los pueblos del norte", es decir, "la lengua polaca es sinónimo de lengua extranjera". En suma, la recepción cervantina del léxico eslavo pudo encauzarse a través de estos materiales de divulgación; pero también a ello debió contribuir la estrecha relación de «lo polaco» con la cosmovisión septentrional áurea, coincidiendo además con el mayor prestigio internacional del reino de Polonia en el s. XVI, gracias a la figura de uno de sus monarcas más célebres, Segismundo III Vasa (1566-1632), rey también de Suecia y Gran Duque de Lituania y Finlandia, que acabaría convirtiéndose en el aliado natural del Sacro Imperio Romano-Germánico en el norte de Europa como consecuencia de su ferviente catolicismo. Para hacerse una idea más exacta de las relaciones hispano-polacas y del papel emergente de Polonia en la política europea, aunque se centre en los primeros tiempos del gobierno del Conde-Duque de Olivares, época ya alejada de las coordenadas temporales de Cervantes, sin embargo, no está de más consultar el libro digital de Skowron (2008), así como la reseña sobre el mismo de Urjascz-Raczko (2009).

12. Existe, no obstante, otra propuesta de interpretación: en su pionero análisis onomástico de los caracteres del Persiles, Reyre (2003: 111) esgrime una explicación alternativa a la exégesis de Romero adoptada por nosotros, pareciendo que la rechaza de plano, pues afirma categóricamente que "la etimología cervantina es otra: el prefijo Brada, del latín brandere, «arder, quemar», recuerda al nombre de otro personaje violento del Quijote, el gigante Brandabarbarán (I, 18)", de suerte que "Cervantes desarrolla el tema del fuego contenido en Bra(n)damiro, contando el incendio de la isla por sus partidarios", lo que constituye "otro ejemplo de la función del nombre como núcleo narrativo" (Reyre, 2003: 111). Ahora bien, por muy plausible que sea la propuesta desde el punto de vista estético, sin embargo, desde el filológico no se puede sostener de ningún modo, por cuanto la etimología aducida se fundamenta en datos erróneos e inexactos, por no decir falsos: en el latín clásico -el registro que mejor podía conocer Cervantes-, no existe formación alguna verbal que sea /brandere/, ni tan siquiera en etapas posteriores, como el tardío o el medieval, tal y como se colige de la consulta de los diccionarios más solventes y los lexicones más especializados (A.A. V.V. [TLG], 1900-1906; Souter, 1949; Du Cange, 1954 [1 1 ed. 1883-1887]; Niermeyer, 1976; y Bréal \& Bailly, 1922), y lo más similar, a efectos fónicos, a este inventado brandere que recogen todos estos materiales es un vocablo totalmente diferente, /brandeum/, un helenismo adoptado por el latín cristiano, que significa «cinta o faja, generalmente blanca, para cubrir las reliquias de los santos» y se atestigua en la Epistula, 4, 30 de Gregorio Magno; por otra parte, las nociones de «quemar, arder» en latín fueron conformadas con los verbos /uror/ y /ardeo/, siendo este último el más frecuente de ambos y el que ha generado mayor abundancia y variedad de usos expresivos, como dan sobrada cuenta las más de dos páginas que le dedica el $T L G$; y, por último, lo que sí reflejan algunos de los lexicones mentados (tanto el de Niermeyer como el de Du Cange), y de donde muy probablemente ha derivado la defectuosa fundamentación morfológica de Reyre, es el hecho de que en latín medieval, concretamente, en el s. XIII, se testimonian los sustantivos /brando, -onis/ y /branda/ (variante femenina), con los significados ígneos de «pavesa, antorcha, tea..etc», originados a partir de voces germánicas. Aparte de este inconveniente de peso, a efectos literarios, tal alternativa nos parece de una simplista y rebuscada audacia, dado que, y en contradicción con la que la autora llega a afirmar en su estudio (Reyre 2003: 104-105), las 
paz» entra en contradicción con el esquema argumental en que se intercala el comportamiento y actitudes del Bárbaro, así como con la presentación al lector en el pasaje acotado de I, 4 (pp. 149-150), de manera que la ironía de la denominación realza la particularidad ontológica de Bradamiro, esto es, su triple carácter de «menospreciador de toda ley», «arrogante sobre la misma arrogancia y atrevido tanto como él mismo».

\section{RESULTADOS DE LA REELABORACIÓN CERVANTINA RESPECTO DEL MODELO VIRGILIANO}

Del análisis intertextual llevado a cabo, pueden inferirse tres resultados esenciales tanto con respecto al grado de vinculación entre ambos caracteres, Mecencio y Bradamiro, como al proceso transformativo aplicado por Cervantes y a su integración estética dentro de los resortes creativos del Persiles.

En primer lugar, la caracterización tripartita de Bradamiro sedimenta dos hipotextos virgilianos, correspondientes con las expresiones que en los vv. 647648 del libro VII conforman precisamente los rasgos definitorios del personaje Mecencio. Si bien Cervantes prescinde del componente criminal y truculento, atestiguado en los vv. 481-488 del libro VIII, no obstante, potencia mediante su selección léxica, así como con la construcción diegético-ficcional del capítulo cuarto, otros rasgos adicionales de Mecencio, como la soberbia, y determinados valores connotativos estructurantes, como es el caso de la noción «violencia».

En segundo lugar, la caracterización de Bradamiro se ejemplifica con una determinada articulación argumental -segmentable en dos episodios-, articulación que incorpora en apretada síntesis tanto la atmósfera general de los Libros VII-X como ciertos detalles argumentales de los vv. 689-908 del Libro X, concernientes a las últimas acciones del personaje virgiliano, elementos estos que no se preservan en su factura originaria, sino que son objeto de reelaboración mediante procedimientos de inversión.

$\mathrm{Y}$ en tercer lugar, el tratamiento cervantino, por el cual se asimilan los materiales virgilianos, conjuga algún que otro conservadurismo con sendas innovaciones, a saber: por un lado, las estrategias de enfatización hiperbólica en un contexto negativo, de modo que el diseño obtenido estará sujeto a una hiperbolización degradadora, radicalmente opuesta a la exagerada idealización que se aplica a las entidades heroicas; $y$, por otro, la configuración ironizante de la onomástica /Bradamiro/, mediante la cual se acentúan los valores no heroicos que encarna el personaje. A estas líneas maestras de reelaboración se añaden otros recursos, como la modulación estilística de la lengua cervantina, la ideología tridentina y el etnocentrismo evangelizador que hacen mella en nuestro novelista o, incluso, la reinterpretación creativa de caracteres prototí- 
picos de la tradición grecobizantina (los bandidos, vaquerizos, piratas) ${ }^{13}$ y el juego intertextual con el comienzo de las Etiópicas ${ }^{14}$.

De ahí que el personaje Bradamiro con su caracterización, onomástica y desarrollo argumental, sea un Mecencio repristinizado, al que se superpone la máscara alegórica de los Bárbaros, constituyendo, por ende, la degradación por antonomasia o, si se prefiere, la irritante exaltación de las imperfecciones.

Bajo esta óptica, Bradamiro, por un lado, eclipsa a la figura esquemática o monolítica de Corsicurvo, que representa el polo menos marcado dentro de la ontología «Bárbara», y es ante todo un mero recurso técnico, del que se sirve Cervantes para plasmar el concepto genérico de «Bárbaro» o, en otras palabras, su más descarnada abstracción, en el comienzo mismo de la Historia Septentrional; por otro, materializa el más expresivo contrapunto de la idealización heroica, a la que se amoldan los protagonistas Periandro y Auristela, coronados con la perfección física y moral.

\section{BIBLIOGRAFÍA CITADA}

AAVV (1900-1906). Thesaurus Linguae Latinae, II. Leipzig: B. G. Teubner.

13. Lozano Renieblas (1998: 128-140) nos proporciona iluminadoras bazas para respaldar el hecho de que Bradamiro también represente la específica reelaboración de un convencionalismo de la novela griega, esto es, la figura paradigmática de los «bandidos (vaquerizos o boukóloi) / piratas» y su función ficcional y argumental. Así, por ejemplo, sostiene que "el rapto de los protagonistas es un componente imprescindible para el desarrollo de la trama en las novelas de tipo griego: sin rapto, no hay novela. En las novelas helenísticas esta función está encomendada a los boukóloi, o vaqueros del Nilo: una tribu feroz que vivía en el Delta del Nilo, famosa por su crueldad. Ahora bien, el Persiles no sitúa sus aventuras en el Mediterráneo oriental, sino en el septentrión, que para el s. XVII se correspondía con el mundo desconocido. Por lo tanto, Cervantes tiene que buscar seres más acordes con las exigencias del espacio ajeno para cumplir la función de raptores de los protagonistas. Elige, como sustitutos de los boukóloi del Nilo, a los habitantes de una isla irreal -pero no fabulosa- poblada por bárbaros, que puede ubicarse en los linderos entre el mundo conocido y el desconocido: al noroeste del archipiélago británico" (Lozano Renieblas, 1998: 128); de igual modo, también afirma que "Cervantes eligió cuidadosamente la parte del mundo que, por aquel entonces, mejor podía reemplazar a los Boukóloi del Nilo y cumplir el cometido encomendado a los raptores de los héroes" (Lozano Renieblas, 1998: 132-133), de la misma manera que, más adelante, indica que "estos ejemplos son suficientes para señalar que, en efecto, Cervantes se ocupó de que el espacio donde habían de operar los bárbaros tuviera tradición de piratería y, al mismo tiempo, respondiera al ideario literario en el plano artístico" (pág. 134). Además, Renieblas enriquece estas consideraciones con un panorama general de los posibles antecedentes literarios, tanto europeos como grecolatinos, que han incidido en la elaboración de la conducta y costumbres del pueblo Bárbaro, así como del espacio isleño en que mora esta tribu de salvajes persilianos, señalando a un tiempo las conexiones morales, etnográficas y espaciales que guardan dichos modelos con el colectivo de los Boukóloi -y demás caracteres asimilables- de la novelística griega.

14. Esta última dimensión contribuiría a refrendar nuestra hipótesis de que el diseño de Bradamiro también posee ingredientes heliodóricos, al constituirse probablemente como contrapunto del comedido Tíamis, jefe de los bandidos que toman como rehenes a Teágenes y Cariclea, en el arranque de la novela, y que, por tanto, se basaría en una amalgama de Virgilio con Heliodoro. Sobre esta cuestión específica nos hemos ocupado en un trabajo anterior, al bosquejar las características y problemas que presenta la contaminación entre ambos influjos dentro del Persiles (Alarcos Martínez, 2011: 315-322). 
Alarcos Martínez, Miguel (2011). «Casos de contaminatio entre Heliodoro y Virgilio en el Persiles: problemática y generalidades», en Perfiles de Grecia y Roma (Actas del XII Congreso de la SEEC), II. Madrid: Estudios Clásicos, pp. 315-322.

Bréal, Michel y Bailly, Anatole (1922). Dictionnaire Étymologique Latin. Paris: Hachette, (dixième edition).

Cervantes, Miguel de (2006). Don Quijote de La Mancha, A. Blecua (ed.). Madrid: Espasa-Calpe.

Cervantes, Miguel de (2001). Novelas Ejemplares. J. García López (ed.). Barcelona: Crítica.

Cervantes, Miguel de (2004). Historia Septentrional. Los trabajos de Persiles y Sigismunda, C. Romero Muñoz (ed.). Madrid: Cátedra (5. ${ }^{a}$ edición).

Du cange, Glossarium Mediae et Infimae Latinitatis, I, Graz-Austria, 1954 [1. a ed. 18831887].

Émesa, Heliodoro de (1954). Historia Etiópica de los Amores de Teágenes y Cariclea, traducida en romance por Fernando de Mena (1587), F. López Estrada (ed.). Madrid: Biblioteca Selecta de Clásicos Españoles, Serie II, vol. XIV.

González Vázquez, José (1979-1980). «Mezencio: su caracterización a través de las imágenes (Aen. X, 689-772)», CFC (Cuadernos de Filología de la Complutense). 16, pp. 127-138.

López Pinciano, Alonso (1953 y 1973). Philosophía Antigua Poética (1596), A. Carballo Picazo (ed.), Madrid: CSIC.

López Pinciano, Alonso (1998). Obras completas (I): Philosophía antigua poética, J. Rico Verdú (ed.). Madrid: Turner.

Lozano Renieblas, Isabel (1998). Cervantes y el mundo del Persiles. Alcalá de Henares: Centro de Estudios Cervantinos.

Marasso, Arturo (1937a). «Fuentes virgilianas del Quijote», Norte, 3, 19, pp. 1-2.

Marasso, Arturo (1937b). Cervantes y Virgilio. Buenos Aires: Instituto Cultural Joaquín V. González.

Niermeyer, J. F. (1976). Mediae Latinatis Lexicon Minus. Leiden: E. J. Brill.

Olao Magno (1949 [1539]). Carta marina et descriptio septemtrionalium terrarum ac mirabilium rerum in eis contentarum, J. Kroom (ed.). Malmö: Suecia.

Olao Magno (2001 [1555]). Storia dei popoli settentrionali. Usi, costumi, credenze (Historia de gentibus septemtrionalibus), G. Monti (ed. y trad.). Milán: BU R Classici.

Oroz, J. (1981). «Figura y función de Mecencio en Virgilio, con una perspectiva sobre la escena final de la Eneida», Helmántica (Revista de Filología Clásica y Hebrea). 32 (97-98), pp. 275-277.

Ortelio, Abraham (1612). Teatrum orbis terrarum, Antuerpiae, 1570 (trad. española: Teatro del Orbe de la tierra, Amberes, Imprenta Plantiniana).

Ortelio, Abraham (1578). Synonymia geographica, sive populorum, regionum, insularum, Amberes: Imprenta Plantiniana.

Pelorson, Jean-Marc. (2003). «El desafío del Persiles», Anejos de Criticón. 16, pp. 7-93.

Reyre, Dominique (2003). «Estudio onomástico», Anejos de Criticón. 16, pp. 97-127.

Schevill, Rudholf (1908). «Studies in Cervantes. Persiles y Sigismunda. III. Vergil's Aeneid», Transactions of the Connecticut Academy of Arts and Sciences, 13, pp. 475-548.

Skowron, Ryszard (2008). Olivares, los Vasa y el Báltico. Polonia en la política internacional de España en los años 1621-1632 (trad. española: ed. digital), Varsovia: Ed. Ruj (ed. original en polaco: 2002).

Souter, Alexander (1949). Glossary of Later Latin to 600 A. D. Oxford: Clarendon Press. Támara, Francisco de (1556). El libro de las costumbres de todas las gentes del mundo, $y$ de las Indias. Amberes: Martín Nucio.

Tasso, Torcuato (1832). La Jerusalén libertada, trad. de A. Izquierdo de Wasteren (a partir de la francesa de 1774, que se publicó, corregida, en 1814). Madrid: Imprenta de Tomás 
Jordán, disponible en http://books.google.es/books?id=enkNAAAAYAAJ\&printsec=frontcover\&hl $=$ es\&source $=\mathrm{gbs}$ ge summary_r\&cad $=0 \# \mathrm{v}=$ onepage $\& \mathrm{q} \& \mathrm{f}=$ false $]$.

Tasso, Torcuato (1964). Discursi dell'arte poetica (1594) e del poema eroico (1567-1570), L. Poma (ed.). Bari: Laterza.

Urjascz-Raczko, Matylda (2009). «Olivares, los Vasa y el Báltico. Polonia en la política internacional de España en los años 1621-1632» (reseña del trabajo de R. Skowron), BROCAR, 33, pp. 305-308.

Virgilio, Publio Marón (1969). Opera omnia, R. A. B. Mynors (ed.). Oxford: Oxford University Press.

Virgilio, Publio Marón (2000). La Eneida, traducida por G. Hernández de Velasco (1555), V. Bejarano (ed.). Barcelona: Planeta.

Virgilio, Publio Marón (1972). Eneida, trad. (en verso), confrontada con texto latino (e introd.) R. Bonifaz Nuño. México: Bibliotheca Scriptorum Graecorum et Romanorum Mexicana-UNAM, (1. ${ }^{\text {a }}$ ed.; $1 .^{\text {a }}$ reimpr. 2008).

Recibido: 4 de julio de 2013

Aceptado: 12 de diciembre de 2013

\title{
Resumen
}

El presente artículo profundiza en las relaciones intertextuales entre dos personajes, esto es, el cervantino Bradamiro del Persiles y el Mecencio de Virgilio, de manera que se ha pretendido averiguar las claves de la reelaboración ejecutada por Cervantes con respecto a semejante modelo virgiliano - patente en diversos libros de la Eneida-, es decir, tanto los procedimientos del proceso reelaborador como su función estética. Para ello, hemos comparado ambas figuras a tenor de su caracterización y desarrollo argumental (inclusive su articulación diegética). Por otra parte, se incluyen cotejos textuales, habida cuenta de que algunas de las reminiscencias virgilianas de Bradamiro remiten a la expresión poética de Virgilio, como consecuencia de las diversas modificaciones operadas por Cervantes sobre tales hipotextos.

Palabras clave: Bradamiro: Mecencio; Cervantes; Virgilio; cotejo intertextual; hipotextos-reminiscencias; función estética de la reelaboración.

Title: A Persiles Character in Comparison to Vergil's Mezentius: Bradamiro, el Bárbaro violento.

\begin{abstract}
The present paper explores in a deep sense the intertextual relation between two characters, i.d., the Cervantine Bradamiro from the romance Los trabajos de Persiles y Sigismunda and Vergil's Mecencius, so we have pretended to work out the reelaboration (not only the procediments, but also its aesthetic function) that Cervantes does respect such Vergilian model, which appears in Aeneid's several books. In order to reach such goal, we have made comparisons regarding with characterization of both figures and their argumental (even narrative) development. In the other hand, we have included textual comparisons, because some of the Bradamiro's Vergilian reminiscences have been originated from Vergil's poetic expression, by several changes that Cervantes has introduced.
\end{abstract}

Key words: Bradamiro; Mecencius; Cervantes; Vergil; Intertextual comparison; Hypotexts-Reminiscences, Reelaboration's aesthetic function. 